The effect of feeding a novel multistrain yeast fraction on European seabass (Dicentrachus labrax) intestinal health and growth performance

Rawling, Mark

http://hdl.handle.net/10026.1/14651

10.1111/jwas.12591

Journal of the World Aquaculture Society

Wiley

All content in PEARL is protected by copyright law. Author manuscripts are made available in accordance with publisher policies. Please cite only the published version using the details provided on the item record or document. In the absence of an open licence (e.g. Creative Commons), permissions for further reuse of content should be sought from the publisher or author. 


\title{
The effect of feeding a novel multistrain yeast fraction on European seabass (Dicentrachus labrax) intestinal health and growth performance
}

\author{
Mark D. Rawling ${ }^{1}$ (1) | Nicola Pontefract ${ }^{1}$ | Ana Rodiles ${ }^{1}$ | \\ llektra Anagnostara ${ }^{1}$ | Eric Leclercq ${ }^{2}$ | Marion Schiavone ${ }^{2,3}$ | \\ Mathieu Castex $^{2}$ | Daniel L. Merrifield ${ }^{1}$
}

${ }^{1}$ Aquatic Animal Nutrition and Health Research Group, School of Biological, Plymouth University, Plymouth, UK

${ }^{2}$ Lallemand SAS, Blagnac, France

${ }^{3}$ Laboratoire d'Ingénierie des Systèmes Biologiques et Procédés, Institut National des Sciences Appliquées de Toulouse, Toulouse, France

\section{Correspondence}

Mark D. Rawling, Animal Nutrition and Animal Health Research Group, School of Biological and Marine Sciences, University of Plymouth, Devon, UK.

Email: mark.rawling@plymouth.ac.uk
Fish were fed a single-strain yeast fraction (SsYF; $2 \mathrm{~g} / \mathrm{kg}$ ) or a multistrain yeast fraction (MsYF; $0.8 \mathrm{~g} / \mathrm{kg}$ ) for 10 weeks. The results demonstrated significant $(p \leq 0.03)$ elevations in weight gain, specific growth rate, protein efficiency ratio, and feed conversion ratio in fish fed the yeast fraction-supplemented diets. In the distal intestine, a significant elevation in microvilli density was observed after 5 and 10 weeks of dietary supplementation with MsYF and SsYF, respectively, compared to control fed fish $(p<0.001)$. A significant elevation $(p=0.02)$ in the perimeter ratio was observed in fish fed diets supplemented with the yeast fractions. After 10 weeks of feeding on the experimental diets, Rt-qPCR demonstrated a significant downregulation $(p<0.05)$ in the stress response genes, heatshock protein 70 ( $h s p 70)$ and proliferating cell nuclear antigen (pcna), in fish fed diets supplemented with the yeast fractions. Significant $(p<0.05)$ elevations in interleukin 1-beta (il1 $\beta)$ and interleukin-10 (il10) gene expression were observed in fish fed diets supplemented with the MsYF compared to the other dietary groups. These findings suggest that feeding an MsYF specifically at a lower incorporation rate $<1 \mathrm{~g} / \mathrm{kg}$, compared to a commercial SsYF at $2 \mathrm{~g} / \mathrm{kg}$, is effective in improving the intestinal health status and growth performance of European seabass.

\section{KEYWORDS}

growth performance, intestinal mucosal health, multistrain yeast fraction, seabass 
Since the turn of the century, the use of prebiotics or functional ingredients with immune modulatory properties has become more prominent across animal feed industry. A key driving force has been the restrictions or ban on the use of prophylactic antibiotic growth promoters in various countries. In a wide range of species, both terrestrial and aquatic, a substantial body of literature exists demonstrating the advantageous effects of feeding functional prebiotics or immune modulatory substances (Kiron, 2012: Ganguly, Dora, Sarkar, \& Chowdhury, 2013; Merrifield \& Ring $\varnothing$, 2014; Song et al., 2014; Pourabedin \& Zhao, 2015; Ringø et al., 2016; Dawood, Koshio, Abdel-Daim, \& Doan, 2018; Dawood, Koshio, \& Esteban, 2018). Beyond the scientific interest of assessing such feeding strategies, the use of a so-called "functional diet" has gained momentum in modern aquaculture, particularly in the European aquaculture sector (Encarnação, 2016). The present study is therefore in line with the ongoing strategy in fish farming, which is the improvement of health and welfare through dietary manipulation, especially with the use of health-promoting additives.

Investigations into the effects of functional feed ingredients from yeasts in animal feeds have largely been directed toward the identification of the functional effects of mannan-oligosaccharide (MOS). Many reports have concluded that the dietary inclusion of MOS can positively influence the health and performance of poultry, swine, and fish (Carbone \& Faggio, 2016; Ferket, Parks, \& Grimes, 2002; Kogan \& Kocher, 2007; Torrecillas, Montero, \& Izquierdo, 2014). Several recent reports have demonstrated the effectiveness of MOS in enhancing the health and growth performance of fish, including juvenile striped catfish, Pangasiandon hypophthalmus (Akter, Sutriana, Talpur, \& Hashim, 2016) and rainbow trout, Oncorhynchus mykiss (Mínguez, Webster, \& Villa, 2016); improving the gut morphology of starry flounder, Platichthys stellatus (Schmidt et al., 2017) and gilthead seabream, Sparus aurata (Eryalçin et al., 2017); and modulating the skin mucous barrier of Atlantic salmon, Salmo salar (Micallef et al., 2017). Although these studies are not directly comparable in terms of dietary regimes, rearing conditions, MOS products, and doses, it is likely that the molecular structure of MOS plays a significant role in the functional effects on the host's intestinal barrier response and physiology (Schiavone et al., 2014). Recent research concerning the yeast cell structure of Saccharomyces cerevisiae led to the discovery of complex strain-specific compositions and architectural characteristics of the cell wall (Schiavone et al., 2014; Schiavone, Sieczkowski, Castex, Dague, \& Marie François, 2015). Among many distinctive traits, yeast strains can differ by the composition of their cell wall with, particularly certain strains differing by the architecture of the polysaccharide network at their surface. MOS derived from the cell wall of $S$. cerevisiae consist of linear chains of $\alpha-1,6$-mannosyl units with short $\alpha-1,2$ and $\alpha-1,3$-linked mannose residues (Schiavone et al., 2015). The most recognized mode of action associated with MOS is in its ability to bind to enteropathogenic bacteria, preventing host colonization. Studies on pathogen adhesion recognition have shown that branched $\alpha$-mannosides of yeast mannans bind with mannose-specific lectin-type receptors (Type 1 fimbriae) of enteropathogenic bacteria, such as Escherichia coli and Salmonella spp., preventing adhesion to the surface glycoproteins of intestinal villi (Firon, Ofek, \& Sharon, 1983). However, a clear correlation between mannan concentration and pathogen immobilization is not always apparent, indicating the involvement of other binding factors. Critically, it appears that the structures of the mannosyls are important determinants of the binding capacity of yeasts (Ganner, Stoiber, Uhlik, Dohnal, \& Schatzmayr, 2013). Detailed biochemical analysis and genetic studies have shown that mannoproteins in S. cerevisiae are highly branched N-glycosylated proteins, while O-mannosylated proteins have short mannose chains (Ballou, 1990). This may partly explain the different abilities of various yeast strains to bind specific bacteria.

Although much research has focused on the immunomodulatory effect of yeast $\beta-1,3 / 1,6$-glucans, MOS are likely to have a direct role in mobilizing the immune response once ingested through the activation of different microbial recognition receptors (MRRs). However, to date, the impact of the arrangement of the polysaccharides network at the surface of the yeast cell wall on the recognition by specific MRRs remains largely unknown.

The scientific literature about the assessment of dietary non-Saccharomyces yeast species as probiotic, prebiotic, or immunostimulant in aquaculture is scarce as highlighted by recent reviews (Gatesoupe, 2007; Navarrete \& Tovar-Ramírez, 2014; Øverland \& Skrede, 2017). We identified fewer than 15 published scientific studies dealing with the assessment of dietary non-Saccharomyces yeast species in aquaculture fish, most of them published after 
2010 (Grammes et al., 2013; Opazo, Fuenzalida, Plaza-Parrochia, \& Romero, 2017; Øverland, Karlsson, Mydland, Romarheim, \& Skrede, 2013; Reyes-Becerril et al., 2011; Reyes-Becerril et al., 2012; Sharma et al., 2018; TapiaPaniagua et al., 2011; Tovar-Ramírez et al., 2010). Specific investigations on the effect of feeding different yeast cell wall fractions from different yeast species or strains is an emerging field in teleost fish (Grammes et al., 2013; Marques, Dhont, Sorgeloos, \& Bossier, 2006; Øverland et al., 2013; Soltanian, Dhont, Sorgeloos, \& Bossier, 2007).

We hypothesize that there could be a benefit to localized immune responsiveness and intestinal integrity of combining different yeast fractions obtained from distinct yeast strains specifically selected for their contrasting cell wall architecture and molecular structure. The present study aimed at investigating the effects of feeding a novel multistrain yeast fraction (MsYF) consisting of two strains of $S$. cerevisiae and one strain of Cyberlindnera jadinii and comparing this to a commercially available single-strain yeast fraction (SsYF) on intestinal health and growth performance of one of the most developed aquaculture species in the Mediterranean, the European seabass (Dicentrachus labrax) (Food and Agriculture Organization, 2008). This study was designed as a preliminary assessment of an MsYF concept combining Saccharomyces and non-Saccharomyces yeast strains prior to further mechanistic studies.

\section{1 | MATERIALS AND METHODS}

\section{1 | Fish and experimental protocol}

A 10-week feeding trial was conducted at the Aquaculture and Fish Nutrition Research Aquarium, University of Plymouth (Plymouth, United Kingdom). European seabass fingerlings were obtained from Aquanatal (Anglesey, United Kingdom). After 4 weeks of acclimation, 225 seabass $(15.5 \pm 0.1 \mathrm{~g}$ ) were randomly distributed into $9 \times 110 \mathrm{~L}$ fiberglass tanks ( 25 fish/tank). The seabass were fed at a fixed rate of $2.0 \%$ of biomass per day, with three feeding times: 9:00 a.m., 1:00 p.m., and 4:30 p.m., and they were batch-weighed weekly to adjust daily feed input. Fish were maintained under a constant 12:12 hr light:dark photoperiod; and water quality parameters were maintained within a suitable range for the European seabass (Person-Le Ruyet, Mahe, Le Bayon, \& Le Delliou, 2004). Water temperature and salinity averaged $24.1 \pm 0.8^{\circ} \mathrm{C}$ and $26.6 \pm 4.3 \mathrm{ppt}$, respectively; dissolved oxygen was maintained between 7.5 and $8 \mathrm{mg} / \mathrm{L} ; \mathrm{pH}$ between 6.8 and 7.5; ammonium between 0.04 and $0.08 \mathrm{mg} / \mathrm{L}$; nitrite between 0.02 and $0.06 \mathrm{mg} / \mathrm{L}$; and nitrate between 54 and $58 \mathrm{mg} / \mathrm{L}$.

\subsection{Feed formulation and diets}

A basal diet was formulated to meet the known nutritional requirements of juvenile European seabass (NRC, 2011) (Table 1). The SsYF product was obtained by extracting the yeast cell wall of a primary grown strain of $S$. cerevisiae and the MsYF product by combining yeast fractions from three specific strains from the Lallemand Yeast Culture Collection (two strains of S. cerevisiae and one strain of C. jadinii). Figure 1 presents the distinct biochemical, biophysical, and selected immune properties of these products. Briefly, total carbohydrates were determined by sulfuric acid hydrolysis (Francois, 2006), and quantitation of total protein was measured by Kjeldahl. Immune assays were performed with mononuclear peripheral blood cells (PBMCs) from healthy volunteers provided by the French Blood Establishment, and monocytes were isolated by Ficoll gradient isolation from a cytapheresis residue obtained from a healthy donor. The PBMCs were cultured for $2 \mathrm{hr}\left(5 \% \mathrm{CO}_{2}-37^{\circ} \mathrm{C}\right)$ on plastic in an macrophage- serum free media medium and were seeded at 1,000,000/well of a 96-well plate to obtain 100,000 monocytes/well after adhesion. After washing with buffer (Hanks balanced salt solution without calcium or magnesium), the remaining cells were monocytes used for experiments on TNF- $\alpha$ secretion and superoxide anion species (RLO). Quantification of TNF- $\alpha$ was performed on supernatants according to Cisbio (30200 Codolet, France) TNF- $\alpha$ Assay kit using the Homogeneous Time Resolved Fluorescence detection technique. The induction of RLO by monocytes was measured after stimulation by Zymosan or yeasts 
TABLE 1 Dietary formulation (\%) and proximate composition of experimental diets

\begin{tabular}{|c|c|c|c|}
\hline & Control & SsYF & MsYF \\
\hline \multicolumn{4}{|l|}{ Dietary formulation (\%) } \\
\hline Fishmeal LT94 ${ }^{\mathrm{a}}$ & 15.0 & 15.0 & 15.0 \\
\hline Soybean protein concentrate ${ }^{b}$ & 38.9 & 38.9 & 38.9 \\
\hline Corn gluten meal & 16.0 & 16.0 & 16.0 \\
\hline Fish oil $^{\mathrm{c}}$ & 11.9 & 11.9 & 11.9 \\
\hline Corn starch ${ }^{\mathrm{d}}$ & 16.6 & 16.6 & 16.6 \\
\hline Vitamin + mineral mix & 1.0 & 1.0 & 1.0 \\
\hline CMC-binder & 0.5 & 0.5 & 0.5 \\
\hline SsYF product ${ }^{f}$ & - & 0.2 & - \\
\hline MsYF product ${ }^{g}$ & - & - & 0.08 \\
\hline \multicolumn{4}{|l|}{ Proximate composition } \\
\hline Dry matter (DM; \%) & 94.5 & 94.8 & 93.5 \\
\hline Crude protein (\%DM) & 45.0 & 44.7 & 44.9 \\
\hline Crude lipid (\%DM) & 15.6 & 15.5 & 15.4 \\
\hline Ash (\%DM) & 5.6 & 5.2 & 5.9 \\
\hline Gross energy (MJ/kg) & 21.72 & 21.30 & 20.21 \\
\hline
\end{tabular}

Note. MsYF: multistrain yeast fraction; SsYF: single-strain yeast fraction.

a United fish products (Aberdeen, United Kingdom).

b HP-110, Hamlet Protein, Saturnvej 5, DK-8700 Horsens, Denmark (crude protein 57.5\%; ash 6.8\%; moisture 6.5\%; lipid 2.5\%).

c Epanoil (Seven Seas Ltd, Feltham, Middlesex, United Kingdom).

d Sigma-Aldrich (Poole, United Kingdom).

e Premier nutrition vitamin premix; each $1 \mathrm{~kg}$ of premix contains: $12.1 \%$ calcium, ash $78.7 \%$, vit A $1.000 \mu \mathrm{g} / \mathrm{kg}$, vit D3 $0.100 \mu \mathrm{g} / \mathrm{kg}$, vit E (as alpha tocopherol acetate) 7,000.0 mg/kg, copper (as cupric sulphate) $250.000 \mathrm{mg} / \mathrm{kg}$, magnesium $1.56 \%$, phosphorous $0.52 \%$.

f Single-strain yeast fraction product (AgriMOS; Lallemand SAS, Blagnac, France).

g Multistrain yeast fraction product (Lallemand SAS).

products through chemiluminescence. Differences in the cell wall glycosylation of a specific yeast species was studied by measuring the extension of glycoproteins at the yeast cell surface. To do so, the cell surfaces of each strain were probed with Concanavalin A using an Atomic Force Microscope (Nanowizard III, JPK-Bruker, Haus 13, Eingand B, Berlin, Germany) according to Schiavone et al. (2017). The presence of the specific yeast species composing MsYF is shown by identification using ITS-PCR followed by DNA digestion using restriction enzymes Cfol, Haelll, and Hinfl. DNA extraction was performed directly on the sample dry biomass after Schiavone et al. (2017).

Three experimental diets were tested in triplicate: the basal diet (Control), the basal diet supplemented with a commercial SsYF product at $2 \mathrm{~g} / \mathrm{kg}$ of feed (SsYF; AgriMos, Lallemand SAS, Blagnac, France), and an MsYF product at $0.8 \mathrm{~g} / \mathrm{kg}$ of feed (MsYF; Lallemand SAS). In-feed incorporation rates were selected based on the manufacturer's instructions. Each diet was produced by mechanically stirring the ingredients into a homogenous mixture using a Hobart food mixer (Hobart Food Equipment, Orton Southgate, Peterborough, United Kingdom, model no: HL1400-10STDA mixer). Warm water was added to reach a consistency suitable for cold press to form 1-mm pellets (PTM Extruder system, model P6, Plymouth, United Kingdom). The nutritional profile for each diet was determined according to AOAC (2007) official protocols (Table 2).

\section{3 | Sampling schedule}

After 5 and 10 weeks of feeding, a total number of six and nine fish per experimental group, respectively, were randomly netted and euthanized following Home Office Schedule 1 procedures (United Kingdom). Fish were individually measured for body weight (BW; $\pm 0.1 \mathrm{~g}$ ); fork length ( $\mathrm{FL} ; \pm 1 \mathrm{~mm}$ ) and the posterior intestine (PI) were sampled using 
(a)

\begin{tabular}{|c|c|c|}
\hline Products & Total carbohydrates & Protein \\
\hline SsYF & $63 \%$ & $22 \%$ \\
\hline MsYF & $56 \%$ & $30 \%$ \\
\hline
\end{tabular}

(c)

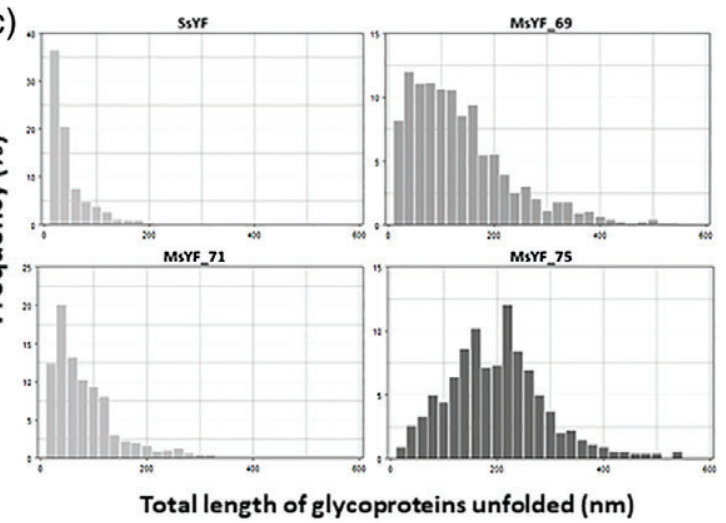

(b)

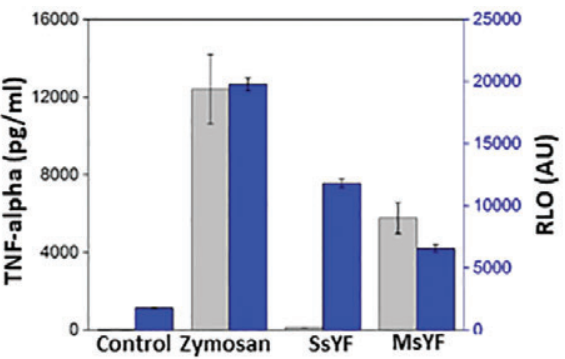

(d)

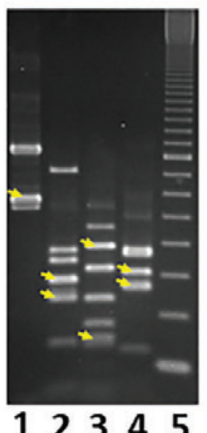

1/ MsYF non digested 2/ MsYF digested with Cfol $3 /$ MsYF digested with HaellI 4/ MsYF digested with Hinfl 5/ 100 bp DNA Ladder

FIGURE 1 (a) Biochemical composition of the test products determined by the sulfuric acid hydrolysis method for total carbohydrates and Kejdahl method for protein. Total carbohydrates were calculated by adding $\alpha$-glucans, $\beta$-glucans, mannans, and chitin; (b) secretion of reactive oxygen species (RLO) and TNF- $\alpha$ by human monocytes incubated with media (control), Zymosan, SsYF, or MsYF; (c) total length of glycoproteins fully unfolded at the surface of the single strain of Saccharomyces cerevisiae (SsYF) and of each strain of the multistrain product (MsYF strain 1, MsYF strain 2, and MsYF strain 3); (d) PCR (ITS) with primers ITS1 and ITS4, followed by DNA digestion by Cfol, Haell, or Hinfl. The presence of $C$. Jadinii was confirmed by the presence of its restriction profile (shown by yellow arrows). The other bands match the restriction profile of $S$. cerevisiae. ITS: internal transcribed spacer; MsYF: multistrain yeast fraction; PCR: polymerase chain reaction; RLO: superoxide anion species; SsYF: single-strain yeast fraction; TNF: tumor necrosis factor

TABLE 2 Primer pair sequences, gene name abbreviations, annealing temperature (anneal tm in ${ }^{\circ} \mathrm{C}$ ), amplicon size (bp), and primer efficiency (eff) for genes used for real-time PCR

\begin{tabular}{|c|c|c|c|c|}
\hline Gene name & $\begin{array}{l}\text { Primer } \\
\text { name }\end{array}$ & $\begin{array}{l}\text { Accession } \\
\text { number }\end{array}$ & Primer sequence $\left(5^{\prime}-3^{\prime}\right)$ & $\begin{array}{l}\text { Aneal } \\
\text { tm/amplicon/eff }\end{array}$ \\
\hline \multirow{2}{*}{$\begin{array}{l}\text { Glyceraldehyde 3-phosphate } \\
\text { dehydrogenase }\end{array}$} & gapdh-fwd & AY863148 & TGCTGCTTTCACCTCCAAGAA & $60 / 75 / 1.9$ \\
\hline & gapdh-rev & & CCATGTACTCCAGGTCGATGAA & \\
\hline \multirow[t]{2}{*}{$\beta$-Actin } & Bactin-fwd & AJ493428 & ATCCACGAGACCACCTACAA & $60 / 79 / 2.0$ \\
\hline & Bactin-rev & & ACAGCACAGTGTTGGCATAC & \\
\hline \multirow[t]{2}{*}{ Interleukin-1 $\beta$} & $i l 1 \beta-f w d$ & AJ269472 & TTACCCACCACCСACTGACA & $60 / 70 / 2.0$ \\
\hline & il $1 \beta-$ rev & & AAGCCCTTCAGTCTCTCCAT & \\
\hline \multirow[t]{2}{*}{ Interleukin-10 } & il10-fwd & AM268529 & GCTGGGTCTGCTGTTCAACTA & $60 / 66 / 2.1$ \\
\hline & il10-rev & & GCTGCATGGTTTCTGTGTTGTT & \\
\hline \multirow{2}{*}{$\begin{array}{l}\text { Proliferating cell nuclear } \\
\text { antigen }\end{array}$} & pcna-fwd & JQ755266 & TGAAGTGTGCAGGAAACGAAGA & $60 / 65 / 1.9$ \\
\hline & pcna-rev & & GGCGAGTGTGTCTGCATTGT & \\
\hline \multirow[t]{2}{*}{ Heat shock protein 70} & hsp70-fwd & AY423555 & TCCAGCGTGACAAGGTATCTG & $60 / 64 / 1.9$ \\
\hline & hsp70-rev & & TCTTACCGGCAAGCCTTTCA & \\
\hline
\end{tabular}


scanning electron microscopy (SEM), histology, and gene expression analysis. For histological analysis, PI samples were removed and fixed in $10 \%$ marine formalin and maintained at $4^{\circ} \mathrm{C}$ for $48 \mathrm{hr}$. Samples were then transferred to $70 \%$ ethanol for long-term storage. For SEM, PI samples were washed in 1\% S-carboxymethyl-L-cysteine buffer (pH 7.2) before being placed in $2.5 \%$ glutaraldehyde with $0.1 \mathrm{M}$ sodium cacodylate buffer (1:1 vol/vol, $\mathrm{pH} 7.2)$. For gene expression analysis, PI samples ( $<100 \mathrm{mg}$ ) were placed in a $1 \mathrm{~mL}$ RNA-later solution (Applied Biosystems, Paisley, United Kingdom) and stored at $4^{\circ} \mathrm{C}$ for $24 \mathrm{hr}$ and then at $-80^{\circ} \mathrm{C}$ until RNA extraction.

\section{4 | Growth performance calculations}

For analysis of growth performance, 25 fish/tank were bulk-weighed on a weekly basis. Growth and feed performance were assessed based on specific growth rate (SGR), feed conversion ratio (FCR), protein efficiency ratio (PER), and Fulton's condition factor (K). Calculations were made using the following formulae: SGR (\%BW/day) $=100$ $\left[\left(\operatorname{lnBW}_{\mathrm{f}}-\operatorname{lnBW} \mathrm{i}\right) / \mathrm{T}\right] ; \mathrm{FCR}=\mathrm{FI} / \mathrm{WG} ; \mathrm{PER}=\mathrm{WG} / \mathrm{PI} ; \mathrm{K}=\mathrm{BW} / \mathrm{FL}^{3}$, where $\mathrm{BW}_{\mathrm{f}}=$ final BW $(\mathrm{g}), \mathrm{BW}_{\mathrm{i}}=$ initial BW $(\mathrm{g})$, $\mathrm{T}=$ duration of the trial (day), $\mathrm{WG}=$ weight gain $(\mathrm{g}), \mathrm{FI}=$ estimated feed intake $(\mathrm{g}), \mathrm{PI}=$ estimated protein intake $(\mathrm{g})$, and $\mathrm{FL}=$ fork length $(\mathrm{cm})$.

\section{5 | Morphometric and SEM}

Formalin-fixed PI samples were dehydrated (Leica TP1020), embedded in paraffin wax, sectioned at $5 \mu \mathrm{m}$ thickness (Leica RM2235 microtome), and dried in an oven overnight. For each specimen, multiple sections were stained with hematoxylin and eosin (H\&E) and Alcian Blue-PAS to assess the intestinal perimeter ratio (PR), intraepithelial leukocytes (IEL), and goblet cell abundance in the epithelium after Dimitroglou et al. (2009). Image analysis was conducted using Image J 1.47v software (National Institutes of Health, Maryland).

Samples for SEM were dehydrated in a graded ethanol series (30\% alcohol, 50, 70, 90, and 100\% twice) for $15 \mathrm{~min}$ at each step and critically point dried (K850 Emitech, South Stour, Ashford Avenue, Ashford, Kent, United Kingdom) with ethanol as the intermediate fluid and $\mathrm{CO}_{2}$ as the transition fluid. The samples were then sputtercoated (K550 Emitech) with gold and viewed with a JSM 6610 LV scanning electron microscope. For each sample, multiple images were captured at $\times 500-\times 20,000$ magnifications to assess general intestinal integrity. Microvilli density measurements were conducted in Image $J$ using images at $\times 20,000$ magnification according to Dimitroglou et al. (2009). Briefly, micrographs were converted to 8-bit, and the ratio of white/black (i.e., foreground/background) was calculated to give a microvilli density measure (arbitrary units [a.u.]).

\section{6 | RNA extraction and cDNA synthesis}

Total RNA was extracted using a TRI reagent (Ambion, Life technologies, Paisley, United Kingdom) according to the manufacturer's instructions, with some modifications. Briefly, $100 \mathrm{mg}$ intestinal samples were removed from the RNA-later solution, and excess solution was removed by pressing the sample between sterile tissues. The samples were transferred into a tube containing $1 \mathrm{~mL}$ TRI reagent and homogenized for $10 \mathrm{~min}$. Following this, $200 \mu \mathrm{L}$ of chloroform was added, and after mixing, samples were centrifuged at 12,000 g for $15 \mathrm{~min}$. The upper aqueous phase was transferred into a tube containing an equal volume of isopropanol. Mixtures were vortexed and centrifuged at $14,000 \mathrm{~g}$ for $15 \mathrm{~min}$. Supernatants were discarded, and the precipitated RNA pellets were washed using $1 \mathrm{~mL}$ of $75 \%$ ethanol. Total RNA was dissolved in diethylpyrocarbonate water and, to remove any contaminating genomic DNA, was purified using RNeasy Plus Mini Kit according to the manufacturer's instructions (Qiagen, Manchester, United Kingdom). The concentration and quality of RNA in each sample were determined by measuring 260/280 nm and 260/230 absorbance ratios (NanoDrop Technologies, Wilmigton, DE). The integrity of RNA was confirmed on a 1\% Agarose gel. Samples were stored at $-80^{\circ} \mathrm{C}$. A $20-\mu \mathrm{L}$ reaction volume containing of $1 \mu \mathrm{g}$ of total RNA was used for cDNA synthesis, using the iScript cDNA synthesis kit (Bio-Rad, Watford, Herefordshire, United Kingdom). The 
reaction was maintained at $25^{\circ} \mathrm{C}$ for $5 \mathrm{~min}$ and then $42^{\circ} \mathrm{C}$ for $30 \mathrm{~min}$ and was inactivated at $85^{\circ} \mathrm{C}$ for $5 \mathrm{~min}$. The iScript cDNA synthesis kit contains a combination of oligo dTs and random hexamers to work with a wide variety of targets.

\section{7 | Real-time PCR assay}

PCR reactions were performed with the SYBR green method using a Quantstudio 12k Flex Real-time PCR thermal cycler (Applied Biosystems). Duplicate PCR reactions were carried out for each sample analyzed. Each PCR reaction was set on a 384-well plate by mixing $2 \mu \mathrm{L}$ of diluted (1/10) CDNA with $5.5 \mu \mathrm{L} 2 \times$ concentrated iQ SYBR Green Supermix (Bio-Rad), containing SYBR Green as a fluorescent intercalating agent, $0.3 \mu \mathrm{M}$ forward primer, and $0.3 \mu \mathrm{M}$ reverse primer. The primers used and their sequences are presented in Table 3. The thermal profile for all reactions was $10 \mathrm{~min}$ at $95^{\circ} \mathrm{C}$ and then 40 cycles of $15 \mathrm{~s}$ at $95^{\circ} \mathrm{C}$ and $60 \mathrm{~s}$ at $60^{\circ} \mathrm{C}$. Fluorescence monitoring occurred at the end of each cycle. Additional dissociation curve analysis was performed and displayed in all cases for one single peak. $\beta$-actin and gapdh were used as reference genes in each sample in order to standardize the results by eliminating variation in mRNA and cDNA quantity and quality (Bustin et al., 2009). The stability and suitability of gapdh and $\beta$-actin as reference genes were confirmed by generating an expression stability measure " $M$ " for each reference gene using the calculations outlined in Vandesompele et al. (2002). No amplification product was observed in negative controls and no primer-dimer formations were observed in the control templates. Modification of gene expression was represented with respect to the control group being sampled at the same time as the treatment group.

The threshold cycle (Ct), defined as the point at which the fluorescence rises appreciably above the background fluorescence, was determined manually for each run. PCR efficiencies for each set of primers were determined using serial dilutions of $\mathrm{CDNA}(n=3)$ and the resulting plots of $\mathrm{Ct}$ versus the logarithmic $\mathrm{CDNA}$ input using the Equation $\mathrm{E}$ : $(P C R$ efficiency) $=10$ (-1/slope); see Table 2 (Rasmussen, 2001). The normalized expression level (NEL) of target genes were calculated on the basis of $\mathrm{Ct}$ deviation $(\Delta \mathrm{Ct})$ of the unknown sample versus a control sample and expressed in comparison to the reference genes gapdh and $\beta$-actin according to calculations outlined by geNorm manual (http://medgen.ugent.be/ jvdesomp/genorm/) and Vandesompele et al. (2002).

\section{8 | Statistical analysis}

All statistical analyses for realtime-quantitative polymerase chain reaction (Rt-qPCR) data were carried out using the permutation test in R following Ohmel (1996). All other statistical differences (Intestinal morphometry, scanning electron microscopy (SEM), growth performance data) were assessed by one-way ANOVA tests (SPSS version 22, SPSS Inc., IL), with Tukey high significant difference post-hoc test where differences in experimental groups occurred. Significance was accepted at $p<0.05$. Data are presented as mean $\pm S D$.

TABLE 3 Body size, growth, and feed performance of European seabass over the 10-week trial's duration. Mean $\pm S D(n=3)$

\begin{tabular}{llllc} 
& Control & SsYF & MsYF & $p$-Value \\
\hline Initial body weight $(\mathrm{g})$ & $15.5 \pm 0.2$ & $15.5 \pm 0.2$ & $15.4 \pm 0.2$ & 0.987 \\
\hline Final body weight $(\mathrm{g})$ & $33.9 \pm 0.9^{\mathrm{a}}$ & $36.1 \pm 0.6^{\mathrm{b}}$ & $37.1 \pm 1.2^{\mathrm{b}}$ & 0.016 \\
\hline Final condition factor $(\mathrm{K})$ & $1.01 \pm 0.03$ & $1.11 \pm 0.03$ & $1.12 \pm 0.12$ & $>0.05$ \\
\hline Specific growth rate $(\% /$ day) & $1.32 \pm 0.02^{\mathrm{a}}$ & $1.43 \pm 0.03^{\mathrm{b}}$ & $1.42 \pm 0.03^{\mathrm{b}}$ & 0.003 \\
\hline Feed conversion ratio & $1.82 \pm 0.02^{\mathrm{a}}$ & $1.64 \pm 0.02^{\mathrm{b}}$ & $1.53 \pm 0.03^{\mathrm{b}}$ & $<0.001$ \\
\hline Protein efficiency ratio & $0.64 \pm 0.04^{\mathrm{a}}$ & $0.71 \pm 0.02^{\mathrm{b}}$ & $0.84 \pm 0.04^{\mathrm{b}}$ & 0.027 \\
\hline Survival (\%) & $88.0 \pm 3.3^{\mathrm{a}}$ & $94.7 \pm 3.3^{\mathrm{ab}}$ & $98.7 \pm 1.9^{\mathrm{b}}$ & 0.014 \\
\hline
\end{tabular}

Note. Different superscript letters indicate significant differences between treatments. MsYF: multistrain yeast fraction; SsYF: single-strain yeast fraction. 


\section{RESULTS}

\section{1 | Growth performance}

Growth performance data are presented in Table 3. A significant improvement of SGR was observed in fish fed the SsYF (1.43 $\pm 0.03 \% B W /$ day; $p=0.016)$ and MsYF (1.42 $\pm 0.03 \% B W /$ day; $p=0.003)$ diets compared to fish fed the control diet (1.32 $\pm 0.02 \% B W /$ day). In accordance with SGR, there was a significant positive effect $(p=0.016)$ in final BW observed in fish fed SsYF $(36.1 \pm 0.6 \mathrm{~g})$ and MsYF $(37.1 \pm 1.2 \mathrm{~g})$ compared to the control group $(33.9 \pm 0.92 \mathrm{~g})$. Compared to the control group $(1.76 \pm 0.02)$, FCR was significantly lower in fish fed MsYF $(1.53 \pm 0.03 ; p<0.001)$ and SsYF $(1.60 \pm 0.02 ; p=0.002)$. Likewise, significant elevations in PER were observed in fish fed MsYF and SsYF compared to control fed fish ( $p<0.03$ ). After 10 weeks, percentage survival was significantly higher in MsYF $(98.7 \pm 1.9 \% ; p=0.012)$ compared to fish fed the control diet $(88.0 \pm 3.3 \%)$ and the SsYFsupplemented diet $(94.7 \pm 3.3 \%)$.

\section{2 | Intestinal morphometry and SEM analysis}

European seabass from all groups presented an intact intestinal epithelial barrier with extensive mucosal folds, abundant IEL, and numerous goblet cells. Epithelial surfaces appeared healthy with uniform enterocyte formations and densely packed microvilli with no signs of cellular or microvilli disruption or necrosis. Histological morphometric analysis demonstrated that the PI PR was significantly elevated in fish fed SsYF after 5 and 10 weeks (3.61 \pm 0.44 and $4.32 \pm 0.34$, respectively) compared to control fed fish (3.01 \pm 0.42 and $3.21 \pm 0.41$, respectively; Table 4.). In comparison, fish fed the MsYF-supplemented diet exhibited a significant elevation in PR only after 10 weeks (4.22 \pm 0.02$)$ compared to the control group (3.22 \pm 0.11$)$. There were no statistical differences in PR values between the SsYF and MsYF experimental groups throughout the experiment. After 5 weeks, PI microvilli density was significantly elevated in fish fed SsYF (2.90 \pm 1.02 a.u.; $p=0.02)$ and MsYF (4.80 \pm 1.03 a.u.; $p=0.001)$ compared to the control group (1.62 \pm 0.51 a.u.), with a significant elevation in the MsYF compared to SsYF group $(p=0.006)$ (Figure 2a). Likewise, after 10 weeks, the SsYF- (3.51 \pm 0.43 a.u.) or MsYF (3.54 \pm 0.71 a.u.)-fed fish exhibited a significant elevation $(p<0.001)$ in $\mathrm{PI}$ microvilli density compared to fish fed the control diet (1.71 \pm 0.23 a.u.) (Figure $2 b$ ).

TABLE 4 Cytoarchitecture of the distal intestine of European seabass after 5 and 10 weeks of feeding experimental diets. Mean $\pm S D(n=3)$

\begin{tabular}{lcccc} 
& Control & SsYF & MsYF & $p$-Value \\
Week 5 & & & & \\
Perimeter ratio & $3.01 \pm 0.42^{\mathrm{a}}$ & $3.61 \pm 0.44^{\mathrm{b}}$ & $3.21 \pm 0.41^{\mathrm{ab}}$ & 0.04 \\
Mucosal fold length $(\mu \mathrm{m})$ & $325 \pm 106$ & $384 \pm 147$ & $335 \pm 99$ & 0.55 \\
Goblet cells density $(n / 100 \mu \mathrm{m})$ & $17.24 \pm 6.81$ & $9.23 \pm 1.52$ & $11.24 \pm 3.41$ & 0.12 \\
IEL density $(n / 100 \mu \mathrm{m})$ & $4.50 \pm 1.01$ & $8.31 \pm 3.44$ & $9.33 \pm 4.22$ & 0.16 \\
Week 10 & & & & \\
Perimeter ratio & $3.22 \pm 0.11^{\mathrm{a}}$ & $4.32 \pm 0.34^{\mathrm{b}}$ & $4.22 \pm 0.41^{\mathrm{b}}$ & 0.02 \\
Mucosal fold length $(\mu \mathrm{m})$ & $318 \pm 74^{\mathrm{a}}$ & $391 \pm 77^{\mathrm{b}}$ & $337 \pm 96^{\mathrm{ab}}$ & 0.02 \\
Goblet cells density $(n / 100 \mu \mathrm{m})$ & $10.34 \pm 3.41$ & $14.33 \pm 6.94$ & $13.01 \pm 3.84$ & 0.65 \\
IEL $(n / 100 \mu \mathrm{m})$ & $8.81 \pm 4.93$ & $12.54 \pm 4.02$ & $9.72 \pm 3.51$ & 0.20 \\
\hline
\end{tabular}

Note. Different superscript letters indicate significant differences between treatments. IEL: intra epithelial leukocytes; MsYF: multistrain yeast fraction; SsYF: single-strain yeast fraction. 

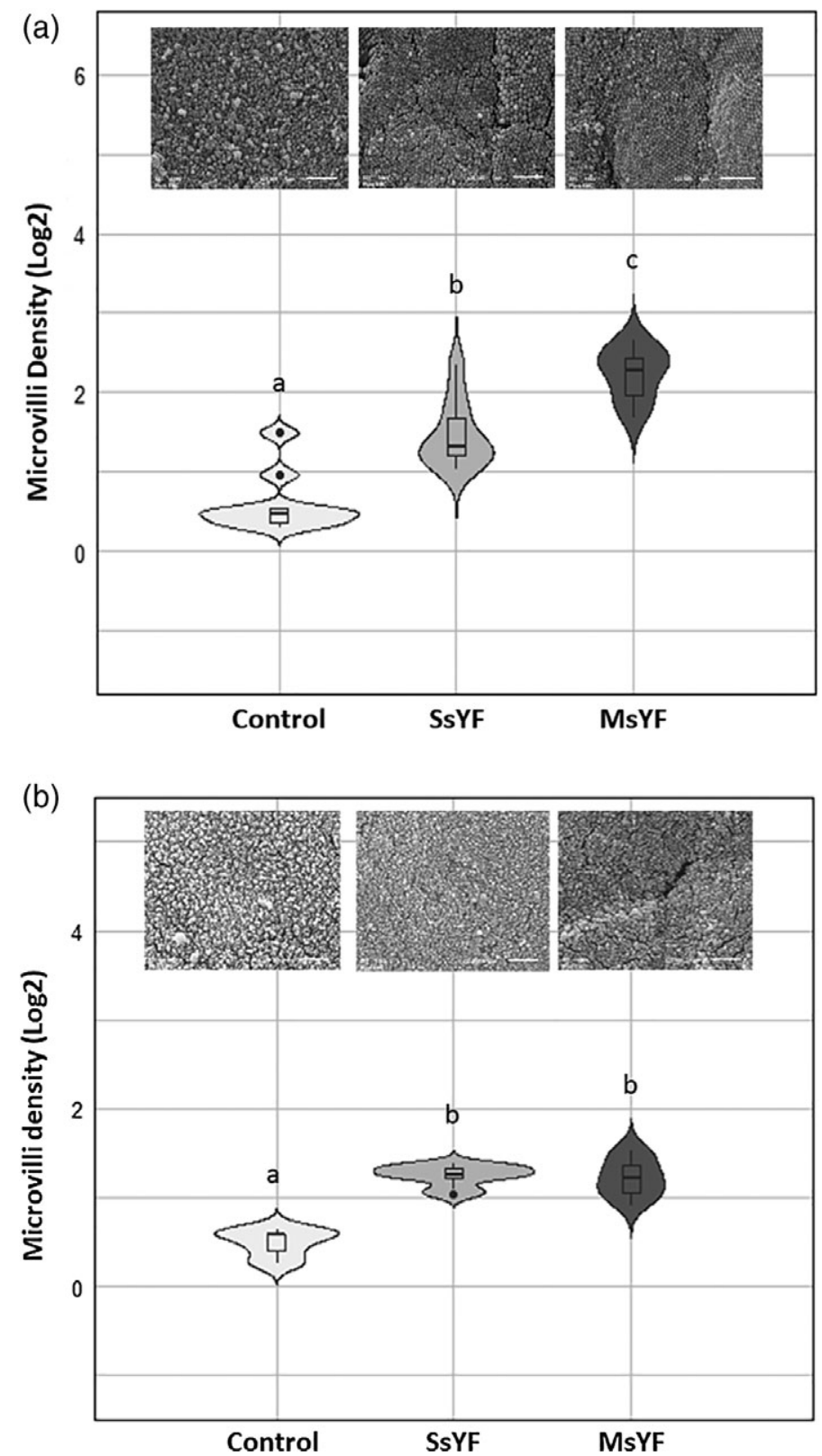

FIGURE 2 Microvilli density (arbitrary units; a.u.) of the distal intestine of European seabass after (a) 5 weeks and (b) 10 weeks of feeding experimental diets. Violin plots show representative SEM images of intestinal samples taken to perform microvilli density analysis (10 samples/treatment). Different superscript letters indicate significant differences between treatments (scale bar $=1 \mu \mathrm{m}$ ). MsYF: multistrain yeast fraction; SsYF: single-strain yeast fraction; SEM: scanning electron microscopy

\section{3 | Intestinal Rt-qPCR}

Gene expression analysis demonstrated a significant downregulation $(p<0.03)$ in $h s p 70$ and pcna expression in both the SsYF (0.17 $\pm 0.06 \mathrm{NEL})$ and MsYF groups (0.11 $\pm 0.07 \mathrm{NEL})$ compared to the control $(0.48 \pm 0.15 \mathrm{NEL})$, with no differences between SsYF and MsYF. In contrast, fish fed the MsYF, but not the SsYF, exhibited a significant 


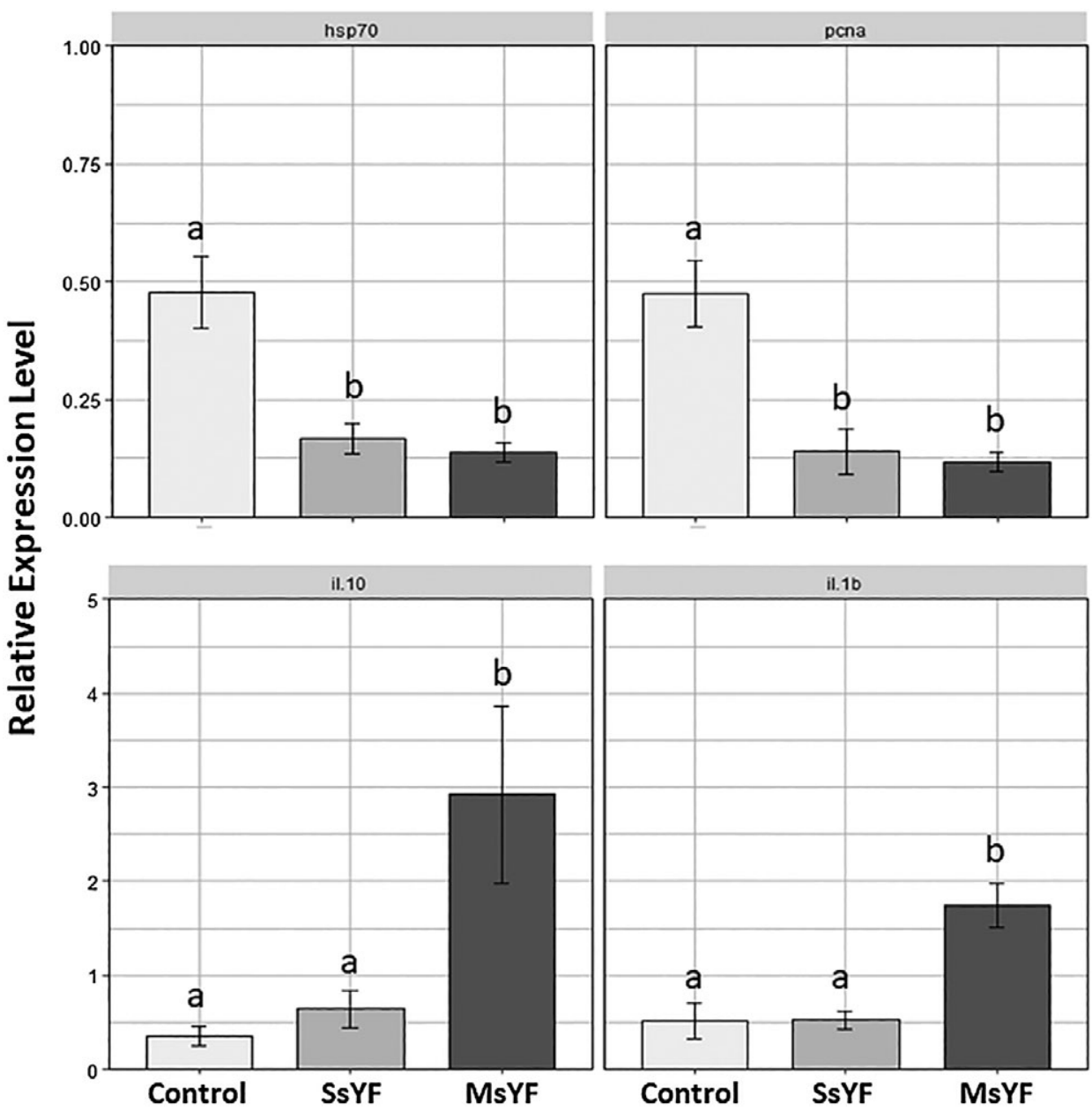

FIGURE 3 Gene expression data (relative expression level) for seabass posterior intestinal samples after 10 weeks of feeding control diet and diets supplemented with SsYF or MsYF (4 samples/treatment). Different superscript letters indicate significant differences for each pairwise comparison between treatments. MsYF: multistrain yeast fraction; SsYF: single-strain yeast fraction

upregulation $(p<0.03)$ in il10 (2.92 $\pm 1.89 \mathrm{NEL})$ and il1 $\beta(1.75 \pm 0.46 \mathrm{NEL})$ gene expression compared to fish fed the control diet (Figure 3).

\section{3 | DISCUSSION}

The current study is the first to report an effect of dietary supplementation with an MsYF product on seabass intestinal health and performance compared to a commercial SsYF product. The positive effects of feeding SsYF rich in MOS on fish growth performance have been well documented previously. Torrecillas et al. (2012) fed European seabass an SsYF rich in MOS at $4 \mathrm{~g} / \mathrm{kg}$ for 60 days and reported significant elevations in BW and length, condition factor, and SGR compared to fish fed the control dietary regime. Similarly, in another study, Torrecillas et al. (2013) reported significant elevations in weight gain, total length, and SGR in seabass fed an SsYF diet compared to a control diet. In other fish species, Rodriguez-Estrada, Satoh, Haga, Fushimi, and Sweetman (2009) fed rainbow trout an SsYF diet at $4 \mathrm{~g} / \mathrm{kg}$ for 12 weeks and reported higher weight gain and SGR compared to fish fed a control diet. The results 
from the current investigation are in line with previous studies confirming that feeding diets containing an SsYF to seabass at a dose of $2 \mathrm{~g} / \mathrm{kg}$ had a positive effect on growth performance. Interestingly, our results indicate that the dietary supplementation of the MsYF at a lower dose ( $<1 \mathrm{vs.} 2 \mathrm{~g} / \mathrm{kg}$ ) achieved a similar level of efficacy in terms of benefits to growth and feed performance compared to seabass fed the SsYF-supplemented diet.

The supplementation of aquafeeds with SsYFs and other functional prebiotics has improved gut morphometry in fish by increasing intestinal absorptive area, villi structure complexity, microvilli density, and height (Torrecillas et al., 2014). Torrecillas et al. (2013) reported an improvement in the cytoarchitecture of the intestinal epithelial barrier of seabass fed diets containing an SsYF rich in MOS at $4 \mathrm{~g} / \mathrm{kg}$ compared to fish fed the control regime. The authors concluded that the effect of the SsYF likely depends on the dose and duration of supplementation as well as on the structure of the SsYF. The current study reported similar effects of feeding an SsYF product rich in MOS at $2 \mathrm{~g} / \mathrm{kg}$ and MsYF products at a lower dose of $0.8 \mathrm{~g} / \mathrm{kg}$ on the intestinal integrity and growth performance of European seabass. Previously, Dimitroglou et al. (2009) reported a significant elevation in microvilli density in rainbow trout fed diets containing SsYF 2 g/kg for 16 weeks. Likewise, Dimitroglou et al. (2011) reported elevations in microvilli density as well as a higher gut absorptive surface in Atlantic salmon fed diets containing an SsYF at $4 \mathrm{~g} / \mathrm{kg}$ for 14 weeks when compared to fish fed the control regime. In the current study, there was a significant elevation in microvilli density in European seabass fed the diets supplemented with the MsYF after 5 weeks compared to SsYF (Figure 2a). To the authors' knowledge, this study is the first to report a beneficial effect of feeding an MsYF product below an inclusion level of $1 \mathrm{~g} / \mathrm{kg}$ on the intestinal morphology of a marine fish.

The fish's intestinal epithelium acts as the first line of defense against potentially harmful substances or pathogens and is continuously in contact with the resident microbiota, the external environment, and dietary compounds. The results of the current study demonstrated a clear difference in the gene expression profiles of selected stress and innate immune response genes in the PI of seabass fed diets supplemented with SsYF or MsYF for 10 weeks. The heat shock protein 70 (hsp70) family is the best studied group of heat shock proteins in aquatic organisms and serves as a stress biomarker, known to be induced during exposure to temperature or salinity, handling, toxins, or other stressors in aquatic organisms (Basu et al., 2002; Roberts, Agius, Saliba, Bossier, \& Sung, 2010). In the current study, fish fed both the SsYF or MsYF exhibited a significant downregulation in gene expression of hsp70 compared to the control diet. Similarly, rainbow trout fed a commercial SsYF rich in MOS and $\beta$-glucans at a dose of $2 \mathrm{~g} / \mathrm{kg}$ exhibited a significant downregulation in gene expression of hsp70 compared to the control regime (Ahmadi, Farahmand, Miandare, Mirvaghefi, \& Hoseinifar, 2014). Likewise, in the present study, a significant downregulation was observed in the gene expression of proliferating cell nuclear antigen (pcna), which plays an important role in cellular and DNA replication (Paunesku et al., 2001), in fish fed the diets supplemented with the yeast fractions. Previously, Torrecillas et al. (2012) reported that, $4 \mathrm{hr}$ postinoculation with Vibrio anguillarum, European seabass fed diets supplemented with a SsYF at $4 \mathrm{~g} / \mathrm{kg}$ exhibited a significantly lower plasma cortisol level compared to fish fed the control regime. In comparison, the current investigation fed an SsYF or MsYF diet at a lower dose and still observed a decrease in gene expression of both hsp70 and pcna. This suggests that both the SsYF and MsYF had an effect on the stress response of European seabass at the transcript level. Furthermore, the significant reduction in pcna expression infers that fish fed the yeast fractions may have a lower level of enterocyte turnover and thus more mature enterocytes that would allow for better nutrients absorption. Indeed, this notion is supported by the observed increase in microvilli density and enhanced feed utilization in fish fed diets containing the yeast fractions.

Feeding European seabass with MsYF triggered a specific immune response in the PI by increasing the expression of both il1 $\beta$ and il10 compared to fish fed the control and SsYF regimes. As a pleitropic proinflammatory cytokine, il $1 \beta$ can affect nearly every cell type, often in concert with other proinflammatory cytokines such as TNFs (as reviewed by Dinarello, 1997; Bird et al., 2002; Huising, Stet, Savelkoul, \& Verburg-van Kemenade, 2004; Savan \& Sakai, 2006). In fish, il $1 \beta$ is one of the first cytokines released during inflammation and is an important effector cytokine of the inflammatory response (Engelsma et al., 2002). The current study demonstrated that il $1 \beta$ gene expression in European seabass fed the MsYF diet was significantly upregulated compared to fish fed the control diet. In contrast, fish fed the SsYF diet displayed no difference in il1 $\beta$ gene expression compared to control group, which is in 
agreement with Torrecillas et al. (2015) using a similar SsYF product at an inclusion level of $1.6 \mathrm{~g} / \mathrm{kg}$. Furthermore, in this study, European seabass fed the MsYF diet for 10 weeks, but not the SsYF, exhibited a significant upregulation in the gene expression of the anti-inflammatory effector cytokine interleukin-10 (il10) compared to the control group. Similarly, Torrecillas et al. (2015) reported an upregulation in il10 posterior intestinal gene expression in European seabass after 8 weeks of feeding diets containing a SsYF at 4 g/kg. Interleukin-10 is an important effector cytokine in the maintenance of the fine balance between a swift and potent immune response against invading pathogens and the control of detrimental pathological injury (Foey \& Picchietti, 2014; Raida \& Buchmann, 2008). The fact that fish fed MsYF exhibited an upregulation in the expression of both il $1 \beta$ and il10 suggests that the dietary inclusion of the MsYF could be promoting a potent but balanced inflammatory response providing immunological protection and maintenance of the intestinal of the intestinal barrier. In summary, we hypothesize that the differences detected in the gene expression profiles of il-1 $\beta$ and il-10 between the SsYF and MsYF groups could, in part, be explained by the different cell wall architectures of the yeast strains composing the products. The combination of the three yeast strains within the MsYF product could activate different pattern recognition receptors compared to SsYF, including toll-like receptors as suggested by the enhanced TNF- $\alpha$ production measured with incubation with human monocytes. This would, in turn, be expected to strengthen the innate immune response to both intra- and extracellular pathogens by activating macrophage and natural killer cell populations in the intestinal mucosal tissue. However, further mechanistic studies are required to investigate this notion.

Several limits inherent to our study and to a majority of similar studies in the field must, however, be highlighted. Even though our results showed positive effects on performance and intestinal morphology parameters, the restricted functional significance of transcriptomic makes inference on immune mechanisms based on immune genes expression difficult. However, the use of gene expression as biomarkers remains practical, cost-effective, and widely used allowing some cross-studies comparative assessment. Recently, several practical feeding studies with European marine fish species were conducted by our group to assess the potential benefit MsYF can bring under commercial farming conditions and confirmed the potential of MsYF as an immune modulation strategy to improve fish health (Rawling et al., 2017; Rawling et al., 2017; Rawling et al., 2018). Finally, it must be noted that, although this study did not investigate the effect of the two yeast products on the intestinal microbiota, it is not possible to exclude a contribution of the gut microbiota to the observed effects on the gene expression of both the stress and immune response markers. Indeed, yeast fraction products are often considered prebiotic, with effects being attributed to changes in the microbiota (Ringø et al., 2010). A previous study reported a modulation of the microbiota of seabass when fed an SsYF diet at $4 \mathrm{~g} / \mathrm{kg}$ compared to fish fed a control regime (Torrecillas et al., 2013). Several other studies report similar effects on other fish species, such as gilthead seabream (S. aurata) or rainbow trout, fed inclusion rates as low as 2 g/kg (Dimitroglou et al., 2009; Dimitroglou et al., 2011).

In conclusion, the impetus of using functional feed additives in aquafeeds is to promote intestinal health and improve fish performance. The present study has demonstrated, for the first time, that dietary inclusion of a novel MsYF at a dose below $1 \mathrm{~g} / \mathrm{kg}$ can enhance the growth performance and intestinal epithelial structure of European seabass by promoting SGR, FCR, and PER and microvilli density and increasing the intestinal surface area compared to fish fed the nonsupplemented diet. Dietary supplementation with the MsYF product also stimulated the innate immune response in the PI of European seabass in a specific fashion compared to fish fed the SsYF in terms of an elevation in the gene expression profiles of il-1 $\beta$ and il-10. This distinct (anti-) inflammatory signature, suggestive of a potent but balanced inflammatory response and achieved at a lower in-feed incorporation rate compared to the SsYF, could have a significant effect on preserving a healthy mucosal barrier, which may in turn enhance protection against enteric pathogens. This preliminary result merits further attention using a dose-response design, analysis of individual strain and strain combinations, and disease challenge studies.

\section{ACKNOWLEDGMENTS}

We thank Matthew Emery and Ben Eynon for their technical support. We also thank Lallemand SAS for the provision of yeast products. 


\section{ORCID}

Mark D. Rawling (D) https://orcid.org/0000-0003-0561-2893

\section{REFERENCES}

Ahmadi, P. Y., Farahmand, H., Miandare, H. K., Mirvaghefi, A., \& Hoseinifar, S. H. (2014). The effects of dietary Immunogen ${ }^{\circledR}$ on innate immune response, immune related genes expression and disease resistance of rainbow trout (Oncorhynchus mykiss). Fish \& Shellfish Immunology, 37, 209-214.

Akter, M. N., Sutriana, A., Talpur, A. D., \& Hashim, R. (2016). Dietary supplementation with mannan oligosaccharide influences growth, digestive enzymes, gut morphology, and microbiota in juvenile striped catfish, Pangasianodon hypophthalmus. Aquaculture International, 24, 127-144.

Association of Official Analytical Chemists. (2007). Method 2007-04. Washington, DC: Author.

Ballou, C. E. (1990). Isolation, characterization, and properties of Saccharomyces cerevisiae mutants with non-conditional protein glycosylation defects. Methods in Enzymology, 185, 440-470.

Basu, N., Todgham, A., Ackerman, P., Bibeau, M., Nakano, K., Schulte, P., \& Iwama, G. K. (2002). Heat shock protein genes and their functional significance in fish. Gene, 295, 173-183.

Bird, S., Zou, J., Wang, T., Munday, B., Cunningham, C., \& Secombes, C. J. (2002). Evolution of interleukin-1ß. Cytokine \& Growth Factor Reviews, 13, 483-502.

Bustin, S. A., Benes, V., Garson, J. A., Hellemans, J., Huggett, J., Kubista, M., ... Wittwer, C. T. (2009). The MIQE guidelines: Minimum information for publication of quantitative real-time PCR experiments. Clinical Chemistry, 55, 611-622.

Carbone, D., \& Faggio, C. (2016). Importance of prebiotics in aquaculture as immunostimulants. Effects on immune system of Sparus aurata and Dicentrarchus labrax. Fish \& Shellfish Immunology, 54, 172-178.

Dawood, M. A. O., Koshio, S., Abdel-Daim, M. M., \& Doan, H. V. (2018). Probiotic applications for sustainable aquaculture. Reviews in Aquaculture, 10, 1-18.

Dawood, M. A. O., Koshio, S., \& Esteban, M. A. (2018). Beneficial roles of feed additives as immunostimulants in aquaculture: A review. Reviews in Aquaculture, 10, 950-974.

Dimitroglou, A., Merrifield, D. L., Moate, R., Davies, S. J., Spring, P., Sweetman, J., \& Bradley, G. (2009). Dietary mannan oligosaccharide supplementation modulates intestinal microbial ecology and improves gut morphology of rainbow trout, Oncorhynchus mykiss (Walbaum). Journal of Animal Science, 87, 3226-3234.

Dimitroglou, A., Reynolds, P., Ravnoy, B., Johnsen, F., Sweetman, J., Johansen, J., \& Davies, S. J. (2011). The effect of Mannan oligosaccharide supplementation on Atlantic salmon smolts (Salmo salar L.) fed diets with high levels of plant proteins. Journal of Aquaculture Research Development, 1, 011.

Dinarello, C. A. (1997). Proinflammatory and anti-inflammatory cytokines as mediators in the pathogenesis of septic shock. Chest Journal, 112, 321S-329S.

Encarnação, P. (2016). Functional feed additives in aquaculture feeds. In Aquafeed formulation (pp. 217-237). Cambridge, England: Academic Press.

Engelsma, M. Y., Huising, M. O., van Muiswinkel, W. B., Flik, G., Kwang, J., Savelkoul, H. F. J., \& Verburg-van Kemenade, B. M. (2002). Neuroendocrine-immune interactions in fish: A role for interleukin-1. Veterinary Immunology and Immunopathology, 87, 467-479.

Eryalçin, K. M., Torrecillas, S., Caballero, M. J., Hernandez-Cruz, C. M., Sweetman, J., \& Izquierdo, M. (2017). Effects of dietary mannan oligosaccharides in early weaning diets on growth, survival, fatty acid composition and gut morphology of gilthead sea bream (Sparus aurata, L.) larvae. Aquaculture Research, 48, 5041-5052.

Ferket, P. R., Parks, C. W., \& Grimes, J. L. (2002, May). Benefits of dietary antibiotic and mannanoligosaccharide supplementation for poultry. Multi-State Poultry Meeting, North Carolina State University, Raleigh, NC.

Firon, N., Ofek, I., \& Sharon, N. (1983). Carbohydrate specificity of the surface lectins of Escherichia coli, Klebsiella pneumoniae and Salmonella typhimurium. Carbohydrate Research, 120, 235-249.

Foey, A., \& Picchietti, S. (2014). Immune defences of teleost fish. In D. L. Merrifield \& E. Ringø (Eds.), Aquaculture nutrition: Gut health, probiotics and prebiotics (pp. 14-52). London, England: Wiley.

Food and Agriculture Organization. (2008). Fishery yearbook. Fishery statistics, aquaculture production. Rome, Italy: Author. http://ftp.fao.org/fi/stat/windows/fishplus/aquaq.zip

Francois, J. M. (2006). A simple method for quantitative determination of polysaccharides in fungal cell walls. Nature Protocols, 1, 2995-3000.

Ganguly, S., Dora, K. C., Sarkar, S., \& Chowdhury, S. (2013). Supplementation of prebiotics in fish feed: A review. Reviews in Fish Biology and Fisheries, 23, 195-199.

Ganner, A., Stoiber, C., Uhlik, J. T., Dohnal, I., \& Schatzmayr, G. (2013). Quantitative evaluation of E. coli F4 and salmonella Typhimurium binding capacity of yeast derivatives. AMB Express, 3(1), 62.

Gatesoupe, F. J. (2007). Live yeasts in the gut: Natural occurrence, dietary introduction, and their effects on fish health and development. Aquaculture, 267(1-4), 20-30. 
Grammes, F., Reveco, F. E., Romarheim, O. H., Landsverk, T., Mydland, L. T., \& Øverland, M. (2013). Candida utilis and Chlorella vulgaris counteract intestinal inflammation in Atlantic Salmon (Salmo salar L.). PLoS One, 8, e83213.

Huising, M. O., Stet, R. J. M., Savelkoul, H. F. J., \& Verburg-van Kemenade, B. M. L. (2004). The molecular evolution of the interleukin-1 family of cytokines; IL-18 in teleost fish. Developmental \& Comparative Immunology, 28, 395-413.

Kiron, V. (2012). Fish immune system and its nutritional modulation for preventive health care. Animal Feed Science and Technology, 173, 111-133.

Kogan, G., \& Kocher, A. (2007). Role of yeast cell wall polysaccharides in pig nutrition and health protection. Livestock Science, 109, 161-165.

Marques, A., Dhont, J., Sorgeloos, P., \& Bossier, P. (2006). Immunostimulatory nature of $\beta$-glucans and baker's yeast in gnotobiotic Artemia challenge tests. Fish \& Shellfish Immunology, 20, 682-692.

Merrifield, D. L., \& Ringø, E. (2014). Aquaculture nutrition: Gut health. In Probiotics and prebiotics. West Sussex, England: Wiley and Sons Publishing Company.

Micallef, G., Cash, P., Fernandes, J. M. O., Rajan, B., Tinsley, J. W., Bickerdike, R., ... Bowman, A. S. (2017). Dietary yeast cell wall extract alters the proteome of the skin mucous barrier in Atlantic Salmon (Salmo salar): Increased abundance and expression of a calreticulin-like protein. PLoS One, 12, e0169075.

Mínguez, C., Webster, P. G., \& Villa, M. (2016). Effect of a prebiotic supplementation of mannan oligosaccharide on growth traits and mortality of rainbow trout (Oncorhynchus mykiss). AACL Bioflux, 9, 1260-1264.

National Research Council. (2011). Nutritional requirements of fish. Washington, DC: National Academy Press.

Navarrete, P., \& Tovar-Ramírez, D. (2014). Use of yeasts as probiotics in fish aquaculture. In Sustainable aquaculture techniques. London, England: InTech.

Ohmel, J. R. (1996). Precision intervals for estimates of the difference in success rates for binary random variables based on the permutation principle. Biometrical Journal, 38, 977-993.

Opazo, R., Fuenzalida, K., Plaza-Parrochia, F., \& Romero, J. (2017). Performance of Debaryomyces hansenii as a diet for rotifers for feeding zebrafish larvae. Zebrafish, 14(2), 187-194.

Øverland, M., Karlsson, A., Mydland, L. T., Romarheim, O. H., \& Skrede, A. (2013). Evaluation of Candida utilis, Kluyveromyces marxianus and Saccharomyces cerevisiae yeasts as protein sources in diets for Atlantic salmon (Salmo salar). Aquaculture, 402-403, 1-7.

Øverland, M., \& Skrede, A. (2017). Yeast derived from lignocellulosic biomass as a sustainable feed resource for use in aquaculture. Journal of the Science of Food and Agriculture, 97(3), 733-742.

Paunesku, T., Mittal, S., Protić, M., Oryhon, J., Korolev, S., Joachimiak, A., \& Woloschak, G. E. (2001). Proliferating cell nuclear antigen (PCNA): Ringmaster of the genome. International Journal of Radiation Biology, 77, 1007-1021.

Person-Le Ruyet, J., Mahe, K., Le Bayon, N., \& Le Delliou, H. (2004). Effects of temperature on growth and metabolism in a Mediterranean population of European sea bass, Dicentrarchus labrax. Aquaculture, 237(1-4), 269-280.

Pourabedin, M., \& Zhao, X. (2015). Prebiotics and gut microbiota in chickens. FEMS Microbiology Letters, $362,15$.

Raida, M. K., \& Buchmann, K. (2008). Development of adaptive immunity in rainbow trout, Oncorhynchus mykiss (Walbaum) surviving an infection with Yersinia ruckeri. Fish \& Shellfish Immunology, 25, 533-541.

Rasmussen, R. (2001). Quantification on the light cycler. In Rapid cycle real-time PCR, methods and applications (pp. 21-34). Berlin, Heidelberg: Springer.

Rawling, M., Dimitroglou, A., Leclercq, E., Castex, M., Barkas, D., \& Merrifield, D. (2017). Effects of a yeast-based functional additive on the skin and intestinal mucosal surfaces of juvenile gilthead seabream Sparus aurata. Dubrovnik, Croatia: European Aquaculture Society.

Rawling, M., Dimitroglou, A., Leclercq, E., Merrifield, D., Barkas, D., \& Castex, M. (2018). The effects of feeding a novel multistrain yeast fraction on the mucosal responses of juvenile gilthead seabream (Sparus aurata). Montpellier, France: European Aquaculture Society.

Rawling, M., Leclercq, E., Tinsley, J., Noguerra, B., Duhamel, A., King, E., ... Castex, M. (2017). The effects of feeding a new multi-strains yeast fractions concept on seabass (Dicentrachus labrax) and rainbow trout (Oncorhynchus mykiss) mucosal response. Dubrovnik, Croatia: European Aquaculture Society.

Reyes-Becerril, M., Ascencio-Valle, F., Meseguer, J., Tapia-Paniagua, S. T., Moriñigo, M. A., \& Esteban, M. Á. (2012). Debaryomyces hansenii L2-enriched diet enhances the immunity status, gene expression and intestine functionality in gilthead seabream (Sparus aurata L.). Aquaculture Research, 43(8), 1107-1118.

Reyes-Becerril, M., Tovar-Ramírez, D., Ascencio-Valle, F., Civera-Cerecedo, R., Gracia-López, V., Barbosa-Solomieu, V., \& Esteban, M. Á. (2011). Effects of dietary supplementation with probiotic live yeast Debaryomyces hansenii on the immune and antioxidant systems of leopard grouper Mycteroperca rosacea infected with Aeromonas hydrophila. Aquaculture Research, 42(11), 1676-1686.

Ringø, E., Olsen, R. E., Gifstad, T. Ø., Dalmo, R. A., Amlund, H., Hemre, G. I., \& Bakke, A. M. (2010). Prebiotics in aquaculture: A review. Aquaculture Nutrition, 16(2), 117-136.

Ringø, E., Zhou, Z., Vecino, J. L. G., Wadsworth, S., Romero, J., Krogdahl, Å., ... Merrifield, D. L. (2016). Effect of dietary components on the gut microbiota of aquatic animals. A never-ending story? Aquaculture Nutrition, 22, 219-282.

Roberts, R., Agius, C., Saliba, C., Bossier, P., \& Sung, Y. (2010). Heat shock proteins (chaperones) in fish and shellfish and their potential role in relation to fish health: A review. Journal of Fish Diseases, 33, 789-801. 
Rodriguez-Estrada, U., Satoh, S., Haga, Y., Fushimi, H., \& Sweetman, J. (2009). Effects of single and combined supplementation of Enterococcus faecalis, mannan oligosaccharide and polyhydroxybutyrate acid on growth performance and immune response of rainbow trout Oncorhynchus mykiss. Aquaculture Science, 57, 609-617.

Savan, R., \& Sakai, M. (2006). Genomics of fish cytokines. Comparative Biochemistry and Physiology Part D: Genomics and Proteomics, 1, 89-101.

Schiavone, M., Déjean, S., Sieczkowski, N., Castex, M., Dague, E., \& François, J. M. (2017). Integration of biochemical, biophysical and transcriptomics data for investigating the structural and nanomechanical properties of the yeast cell wall. Frontiers in Microbiology, 8, 1806.

Schiavone, M., Sieczkowski, N., Castex, M., Dague, E., \& Marie François, J. (2015). Effects of the strain background and autolysis process on the composition and biophysical properties of the cell wall from two different industrial yeasts. FEMS Yeast Research, 15, 2.

Schiavone, M., Vax, A., Formosa, C., Martin-Yken, H., Dague, E., \& François, J. M. (2014). A combined chemical and enzymatic method to determine quantitatively the polysaccharide components in the cell wall of yeasts. FEMS Yeast Research, 14, 933-947.

Schmidt, J., Bischoff, A., Weiss, M., Kim, S., Frickenhaus, S., Slater, M. J., \& Buck, B. H. (2017). Effect of beta-1-3-glucan and mannans on growth and fitness of starry flounder (Platichthys stellatus): A potential new candidate for aquaculture in temperate regions. Journal of FisheriesSciences.com, 11, 17.

Sharma, S., Hansen, L. D., Hansen, J. Ø., Mydland, L. T., Horn, S. J., Øverland, M., ... Vuoristo, K. S. (2018). Microbial protein produced from brown seaweed and spruce wood as a feed ingredient. Journal of Agricultural and Food Chemistry, 66(31), 8328-8335.

Soltanian, S., Dhont, J., Sorgeloos, P., \& Bossier, P. (2007). Influence of different yeast cell-wall mutants on performance and protection against pathogenic bacteria (Vibrio campbellii) in gnotobiotically-grown Artemia. Fish \& Shellfish Immunology, 23, 141-153.

Song, S. K., Beck, B. R., Kim, D., Park, J., Kim, J., Kim, H. D., \& Ringø, E. (2014). Prebiotics as immunostimulants in aquaculture: A review. Fish \& Shellfish Immunology, 40, 40-48.

Tapia-Paniagua, S. T., Reyes-Becerril, M., Ascencio-Valle, F., Esteban, M. A., Clavijo, E., Balebona, M. C., \& Morinigo, M. A. (2011). Modulation of the intestinal microbiota and immune system of farmed Sparus aurata by the administration of the yeast Debaryomyces hansenii L2 in conjunction with inulin. Journal of Aquaculture Research and Development, S1, 1.

Torrecillas, S., Makol, A., Betancor, M. B., Montero, D., Caballero, M. J., Sweetman, J., \& Izquierdo, M. (2013). Enhanced intestinal epithelial barrier health status on European sea bass (Dicentrarchus labrax) fed mannan oligosaccharides. Fish \& Shellfish Immunology, 34, 1485-1495.

Torrecillas, S., Makol, A., Caballero, M., Montero, D., Dhanasiri, A., Sweetman, J., \& Izquierdo, M. (2012). Effects on mortality and stress response in European sea bass, Dicentrarchus labrax (L.), fed mannan oligosaccharides (MOS) after Vibrio anguillarum exposure. Journal of Fish Diseases, 35, 591-602.

Torrecillas, S., Montero, D., Caballero, M. J., Pittman, K. A., Custódio, M., Campo, A., ... Izquierdo, M. (2015). Dietary mannan oligosaccharides: Counteracting the side effects of soybean meal oil inclusion on European sea bass (Dicentrarchus labrax) gut health and skin mucosa mucus production? Frontiers in Immunology, 6, 397.

Torrecillas, S., Montero, D., \& Izquierdo, M. (2014). Improved health and growth of fish fed mannan oligosaccharides: Potential mode of action. Fish \& Shellfish Immunology, 36, 525-544.

Tovar-Ramírez, D., Mazurais, D., Gatesoupe, J. F., Quazuguel, P., Cahu, C. L., \& Zambonino-Infante, J. L. (2010). Dietary probiotic live yeast modulates antioxidant enzyme activities and gene expression of sea bass (Dicentrarchus labrax) larvae. Aquaculture, 300(1-4), 142-147.

Vandesompele, J., De Preter, K., Pattyn, F., Poppe, B., Van Roy, N., De Paepe, A., \& Speleman, F. (2002). Accurate normalization of real-time quantitative RT-PCR data by geometric averaging of multiple internal control genes. Genome Biology, 3 , 0034-1.

How to cite this article: Rawling MD, Pontefract N, Rodiles A, et al. The effect of feeding a novel multistrain yeast fraction on European seabass (Dicentrachus labrax) intestinal health and growth performance. $J$ World Aquacult Soc. 2019;1-15. https://doi.org/10.1111/jwas.12591 